\title{
Estimativa da Área foliar de Plantas Daninhas de Ambiente AQUÁTICO: Pistia stratiotes
}

\author{
Estimate of the Leaf Area of Aquatic Weeds: Pistia stratiotes \\ CARVALHO, L.B. ${ }^{2}$, SOUZA, M.C. ${ }^{3}$, BIANCO, M.S. ${ }^{4}$ e BIANCO, S. ${ }^{5}$
}

\begin{abstract}
RESUMO - A área foliar é uma das principais características para avaliar o crescimento vegetal. Objetivou-se neste trabalho determinar uma equação matemática para estimar a área foliar de Pistia stratiotes a partir de dimensões lineares dos limbos foliares. A pesquisa foi desenvolvida na Universidade Estadual Paulista, Jaboticabal-SP, Brasil. Cem folhas, coletadas no ambiente natural, foram eletronicamente medidas em comprimento (C), largura máxima (L) e área foliar $(\mathrm{AF})$. Os dados de $\mathrm{AF}$ e $\mathrm{C} \times \mathrm{L}$ foram submetidos à análise de regressão linear, determinando-se uma equação matemática para estimar a área foliar da espécie. A análise de variância sobre a regressão linear e a análise de correlação entre os valores de área foliar e estimada foram significativas $(\mathrm{p}<0,01)$. A área foliar de $P$. stratiotes pode ser estimada pela equação: $\mathrm{AF}=0,79499$ (CL).
\end{abstract}

Palavras-chave: equação matemática, Pistia stratiotes, planta aquática.

ABSTRACT - Leaf area is a major characteristic used to evaluate plant growth. This work aimed to determine a mathematical equation to estimate the leaf area of Pistia stratiotes in function of the linear measures of the leaf blades. The experiment was carried out at São Paulo State University, in Jaboticabal-SP, Brazil. Length (L), width (W) and leaf area (LA) of one hundred leaves collected from a natural environment were electronically measured. $L A$ and $L \times W$ data were submitted to linear regression analysis, determining a mathematical equation to estimate the leaf area of the species. ANOVA on linear regression and correlation analysis between the obtained and estimated leaf area values were significant $(p<0.01)$. Leaf area of $\boldsymbol{P}$. stratiotes may be estimated by the equation: $L A=0.79499(L W)$.

Keywords: mathematical equation, Pistia stratiotes. aquatic plant.

\section{INTRODUÇÃO}

Pistia stratiotes, popularmente conhecida por alface-d'água, é uma macrófita aquática nativa da região sul do continente americano, que foi rapidamente disseminada para outras regiões devido ao caráter ornamental de sua folhagem (Kissmann, 1997; Lorenzi, 2000). Contudo, em razãodas densas e extensas colonizações em que ocorre, o que proporciona alta capacidade competitiva, vem causando redução da biodiversidade (Cilliers et al., 1996; Winton \& Clayton, 1996), prejuízos a esportes náuticos, entupimento de tubulações em hidrelétricas e canais de irrigação e prejuízos à produção de energia em usinas hidrelétricas, sendo considerada uma das principais plantas daninhas de ambiente aquático no Brasil (Cavenaghi et al., 2003; Cardoso et al., 2005; Cícero et al., 2007).

\footnotetext{
1 Recebido para publicação em 25.12.2009 e na forma revisada em 18.2.2011.

2 Engọ-Agrọ ., Doutor em Agronomia (Produção Vegetal), Dep. de Biologia Aplicada à Agropecuária, Faculdade de Ciências Agrárias e Veterinárias - FCAV/UNESP, Via de acesso Prof. Paulo Donatto Castellane, s/n, 14884-900 Jaboticabal-SP, Brasil, <agrolbcarvalho@gmail.com>; ${ }^{3}$ Biólogo, Doutorando em Agronomia (Produção Vegetal), FCAV/UNESP, Jaboticabal-SP, Brasil; ${ }^{4}$ Engo-Agr ${ }^{0}$, Mestrando em Agronomia (Produção Vegetal), FACAV/UNESP, Jaboticabal-SP, Brasil. ${ }^{5}$ Professor Adjunto do Dep. de Biologia Aplicada à Agropecuária, FCAV/UNESP, Jaboticabal-SP, Brasil.
} 
Devido à importância de $P$. stratiotes como planta daninha, informações básicas a respeito de sua biologia são essenciais para estudar seu crescimento, dando subsídios para compreender o processo de colonização da espécie. Para isso, o conhecimento da área foliar é fundamental, visto ser esta uma das características mais importantes na avaliação do crescimento vegetal (Carvalho \& Christoffoleti, 2007). Segundo Gamiely et al. (1991), o uso de equações de regressão para estimar a área foliar de plantas é um método simples, rápido, preciso e confiável, que permite acompanhar o crescimento e a expansão foliar de uma mesma planta, até o final do ciclo ou do experimento, sem precisar coletar o material vegetal. Esse método elimina a necessidade de destruição da folha, o que afetaria o desenvolvimento da planta e tornaria equivocada a avaliação do experimento.

A estimativa da área foliar por meio de equações matemáticas tem sido utilizada com boa precisão, sendo um método fácil, rápido e não destrutivo, tornando-se importante para avaliar o crescimento das plantas em campo (Bianco et al., 2007a). Equações de regressão, relacionando área foliar com características dimensionais lineares das folhas, têm sido usadas com sucesso para estimativa da área foliar de plantas daninhas como Amaranthus spp., Ipomoea spp., Leonotis nepetaefolia, Ageratum conyzoides e Sida spp. (Carvalho \& Christoffoleti, 2007; Bianco et al., 2007a, b, 2008a, b). Bianco et al. (2003) e Marchi \& Pitelli (2003) destacaram a importância desse tipo de estudo em plantas aquáticas.

Objetivou-se neste trabalho determinar uma equação matemática para estimar adequadamente a área foliar de $P$. stratiotes a partir da relação entre as dimensões lineares dos limbos foliares, para utilização como método não destrutivo, auxiliar na determinação da área foliar da espécie em pesquisas futuras.

\section{MATERIAL E MÉTODOS}

Esta pesquisa foi realizada na Faculdade de Ciências Agrárias e Veterinárias da Universidade Estadual Paulista(FCAV/UNESP), campus de Jaboticabal, SP, Brasil, em meados de setembro de 2008. As plantas de $P$. stratiotes utilizadas no estudo provinham de ambiente natural, sendo coletadas 100 folhas completamente desenvolvidas, que não apresentavam deformações oriundas de fatores externos, como pragas e doenças.

As folhas coletadas foram acondicionadas em caixas plásticas do tipo gerbox contendo água do próprio reservatório, para evitar perda de turgescência, e rapidamente transportadas ao Laboratório de Biologia e Manejo de Plantas Daninhas da FCAV/UNESP, onde foram determinados o comprimento do limbo foliar ao longo da nervura principal (C), a largura máxima do limbo foliar perpendicular à nervura principal (L) e a área do limbo foliar (AF), utilizando o aparelho eletrônico Portable Area Meter Licor mod. L1 - 3000A.

Para o estudo da relação entre a área do limbo foliar e as dimensões dos limbos foliares, foi realizada a estimativa da equação linear $Y$ $=a . \mathrm{X}$, em que Y expressa o valor da área do limbo foliar; $a$, um parâmetro de reta que corresponde ao percentual de equivalência entre a área foliar; e X, o produto do comprimento (C) pela largura (L). Essa equação foi escolhida, pois Bianco et al. (2005, 2007a,b, 2008a,b) concluíram que a equação linear que passa pela origem pode ser utilizada para estimar a área foliar de Brachiaria plantaginea, Ipomoea spp., Leonotis nepetaefolia, Ageratum conyzoides e Sida spp., além de ser aquela de melhor aplicação prática.

Assim, os dados de área foliar e comprimento $\times$ largura dos limbos foliares de $P$. stratiotes foram submetidos à análise de regressão pelo modelo supracitado e à análise de variância pelo teste $\mathrm{F}$ a $5 \%$ de significância. Para avaliar a correlação entre os valores reais e estimados de área foliar da espécie, foi realizado o teste de correlação de SpearmanRank a 5\% de significância.

\section{RESULTADOS E DISCUSSÃO}

Os valores médios de comprimento, largura e área foliar de $P$. stratiotes foram, respectivamente, de $6,15 \mathrm{~cm}, 5,50 \mathrm{~cm}$ e $27,22 \mathrm{~cm}^{2}$ (Tabela 1), com o comprimento representando $1,12 \mathrm{vez}$ a largura da folha. A maior porcentagem da área foliar de $P$. stratiotes esteve contida na faixa de 25,01 a 
$30,00 \mathrm{~cm}^{2} ; 88 \%$ da área foliar da espécie esteve na faixa de 20,01 a 35,00 $\mathrm{cm}^{2}$ (Tabela 2).

O parâmetro $a$ da equação linear ajustada aos dados de área foliar, em relação ao comprimento $\times$ largura dos limbos foliares de $P$. stratiotes, apresentou o valor de 0,79499, cujo intervalo de confiança aceitável esteve entre 0,786761 e 0,803218 (Tabela 3), sendo a análise de variância da regressão significativa $(\mathrm{p}<0,01)$ (Tabela 4), indicando que a equação representa significativamente a relação referida. Portanto, evidencia-se que a área foliar de $P$. stratiotes aumenta linearmente com o aumento de comprimento $\mathrm{x}$ largura dos limbos foliares; 90\% dos dados puderam ser representados pela equação ajustada (Figura 1). Nesse caso, propõe-se que a área do limbo foliar seja proporcional a um retângulo $\mathrm{C} \times \mathrm{L}$, utilizando-se de um fator de correção a para o cálculo da área foliar da

Tabela 1 - Valor médio e variância dos dados de comprimento ao longo da nervura central, largura máxima e área foliar de Pistia stratiotes

\begin{tabular}{|l|c|c|}
\hline \multicolumn{1}{|c|}{ Característica } & Valor Médio & Variância \\
\hline Comprimento $(\mathrm{cm})$ & 6,15 & 0,34 \\
\hline Largura $(\mathrm{cm})$ & 5,50 & 0,31 \\
\hline Área foliar $\left(\mathrm{cm}^{2}\right)$ & 27,22 & 20,71 \\
\hline
\end{tabular}

Tabela 2 - Porcentagem de limbos foliares distribuídos em diferentes faixas de tamanho relativas à área foliar de Pistia stratiotes

\begin{tabular}{|c|c|}
\hline Área foliar $\left(\mathrm{cm}^{2}\right)$ & Porcentagem \\
\hline $15,00-20,00$ & 6 \\
\hline $20,01-25,00$ & 27 \\
\hline $25,01-30,00$ & 44 \\
\hline $30,01-35,00$ & 17 \\
\hline $35,01-40,00$ & 6 \\
\hline
\end{tabular}

planta (Peressin et al., 1984). Assim, quanto mais próximo à unidade for o valor do fator de correção, mais proporcional a um retângulo será a morfologia do limbo foliar da planta.

Das plantas daninhas aquáticas já estudadas, E. crassipes (Marchi \& Pitelli, 2003) apresentou menor valor do parâmetro $a(0,72)$ que $P$. stratiotes, enquanto para $T$. latifolia (Bianco et al., 2003) o valor observado foi maior $(0,96)$. Isso evidencia que $T$. latifolia apresenta a morfologia do limbo foliar mais proporcional a um retângulo que $P$. stratiotes, ao passo que em $E$. crassipes essa proporcionalidade é menor.

Tabela 3 - Resultado da análise de regressão, pelo modelo y = $a . \mathrm{x}$, dos dados reais de área foliar e comprimento $\mathrm{x}$ largura dos limbos foliares de Synedrellopsis grisebachii

\begin{tabular}{|c|c|c|c|}
\hline$a$ & Erro-padrão & $\begin{array}{c}\text { Limite de } \\
\text { confiança } \\
\text { inferior }\end{array}$ & $\begin{array}{c}\text { Limite de } \\
\text { confiança } \\
\text { superior }\end{array}$ \\
\hline 0,794990 & 0,004147 & 0,786761 & 0,803218 \\
\hline
\end{tabular}

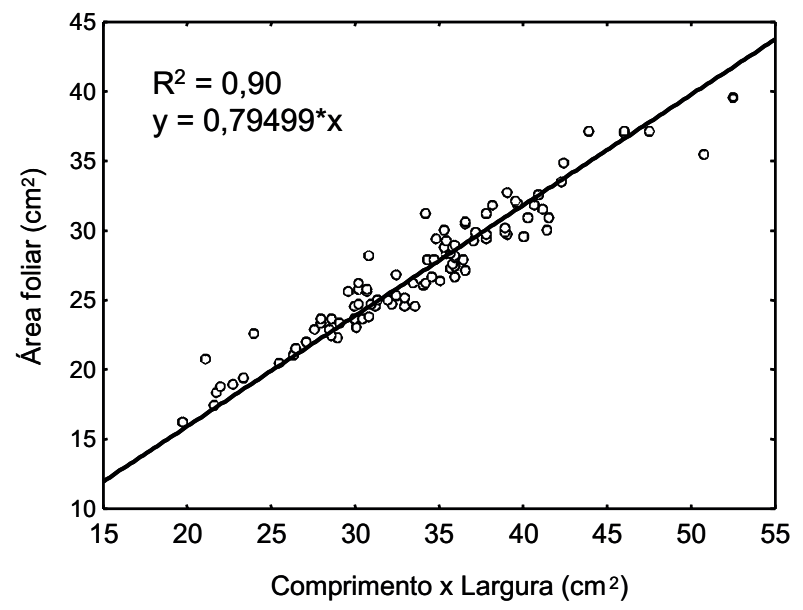

Figura 1 - Relação linear entre a área foliar e o comprimento $\times$ largura dos limbos foliares de Pistia stratiotes.

Tabela 4 - Resultado da análise de variância pelo teste $\mathrm{F}(\mathrm{p}=0,05)$ da regressão dos dados reais de área foliar e o comprimento x largura dos limbos foliares de Pistia stratiotes

\begin{tabular}{|l|r|r|r|c|c|}
\hline \multicolumn{1}{|c|}{ Causa de variação } & \multicolumn{1}{c|}{ SQR } & \multicolumn{1}{c|}{ GL } & QMR & F & p \\
\hline Regressão & $75.942,98$ & 1 & $75.942,98$ & $36.753,10$ & 0,00 \\
\hline Resíduos & 204,56 & 99 & 2,07 & & \\
\hline Total & $76.147,54$ & 100 & & & \\
\hline Total corrigido & $2.050,35$ & 99 & & & \\
\hline Regressão $v$ s total corrigido & $75.942,98$ & 1 & $75.942,98$ & $3.666,87$ & 0,00 \\
\hline
\end{tabular}


O teste de correlação aplicado sobre os valores reais e estimados de área do limbo foliar de $P$. stratiotes foi significativo $(\mathrm{p}<0,05)$, com $95 \%$ de correlação entre os dados analisados (Tabela 5), evidenciando, assim, segundo Bianco et al. (2008b), que a equação ajustada representa significativamente a área do limbo foliar da espécie.

Tabela 5 - Resultado da análise de correlação pelo teste de Sperman-Rank $(\mathrm{p}=0,05)$ sobre os dados reais e estimados de área foliar de Pistia stratiotes

\begin{tabular}{|c|c|c|c|c|}
\hline Variável & $\begin{array}{c}\text { Valor } \\
\text { válido }\end{array}$ & R-Spearman & $\mathrm{t}(\mathrm{N}-2)$ & $\mathrm{p}$ \\
\hline $\begin{array}{l}\text { Área foliar } v s \text { área } \\
\text { foliar estimada }\end{array}$ & 100 & 0,95 & 29,53 & 0,00 \\
\hline
\end{tabular}

Assim, a área do limbo foliar de $P$. stratiotes pode ser estimada satisfatoriamente pela equação $\mathrm{Y}=0,79499(\mathrm{X})$, em que $\mathrm{Y}$ expressa a área foliar estimada e $\mathrm{X}$ representa o produto do comprimento ao longo da nervura principal pela largura máxima do limbo foliar.

\section{LITERATURA CITADA}

BIANCO, S. et al. Estimativa da área foliar de Ipomoea hederifolia e Ipomoea nil Roth. usando dimensões lineares do limbo foliar. Planta Daninha, v. 25, n. 2, p. 325-329, 2007 a.

BIANCO, S.; BIANCO, M. S.; CARVALHO, L. B. Estimativa da área foliar de Ageratum conyzoides usando dimensões lineares do limbo foliar. Acta Sci. Agron., v. 30, n. 4, p. 519-523, 2008a

BIANCO, S.; BIANCO, M. S.; CARVALHO, L. B. Estimativa da área foliar de Leonotis nepetifolia (L.) W.T. Aiton usando dimensões lineares do limbo foliar. Ci. Cult., v. 2 , n. 1 , p. $27-31,2007 \mathrm{~b}$.

BIANCO, S.; CARVALHO, L. B.; BIANCO, M. S Estimativa da área foliar de Sida cordifolia e Sida rhombifolia usando dimensões lineares do limbo foliar. Planta Daninha, v. 26, n. 4 , p. $807-813,2008$ b.

BIANCO, S.; PITELLI, R. A.; BIANCO, M. S. Estimativa da área foliar de Brachiaria plantaginea usando dimensões lineares do limbo foliar. Planta Daninha, v. 23, n. 4, p. 597-601, 2005.
BIANCO, S.; PITELLI, R.A.; PITELLI, A. M. C. M. Estimativa da área foliar de Typha latifolia usando dimensões lineares do limbo foliar. Planta Daninha, v. 21, n. 2 , p. $257-261,2003$.

CARDOSO, L. R. et al. Variabilidade genética entre populações de Pistia stratiotes. Planta Daninha, v. 23, n. 2, p. 181-185, 2005.

CARVALHO, S. J. P.; CHRISTOFFOLETI, P. J. Estimativa da área foliar de cinco espécies do gênero Amaranthus usando dimensões lineares do limbo foliar. Planta Daninha, v. 25, n. 2, p. 317-324, 2007.

CAVENAGHI, A. L. et al. Caracterização da qualidade de água e sedimento relacionados com a ocorrência de plantas aquáticas em cinco reservatórios da bacia do rio Tietê. Planta Daninha, v. 21, p. 43-52, 2003. (Edição Especial)

CÍCERO, E. A. S. et al. Variabilidade genética e sensibilidade de acessos de Pistia stratiotes ao herbicida glyphosate. Planta Daninha, v. 25, n. 3, p. 579-587, 2007.

CILLIERS, C. J. et al. Short- and long-term control of water lettuce (Pistia stratiotes) on seasonal water bodies and on a river system in the Kruger National Park, South Africa. Hydrobiologia, v. 340, n. 1-3, p. 173-179, 1996.

GAMIELY, S. et al. A rapid and nondestructive method for estimating leaf area of onions. HortScience, v. 26, n. 2 , p. $206,1991$.

KISSMANN, K. G. Plantas infestantes e nocivas. 2.ed. São Bernardo do Campo: BASF, 1997. 852 p.

LORENZI, H. Plantas daninhas do Brasil: terrestres, aquáticas, parasitas e tóxicas. 3.ed. Nova Odessa: IPEF, 2000 $640 \mathrm{p}$.

MARCHI, S. R.; PITELLI, R. A. Estimativa da área foliar de plantas daninhas de ambiente aquático: Eichhornia crassipes. Planta Daninha, v. 21, p. 109-112, 2003. (Edição Especial).

PERESSIN, V. A.; PITELLI, R. A.; PERECIN, D. Métodos para estimativa da área foliar de plantas daninhas. 4 Cassia tora L. Planta Daninha, v. 7, n. 1, p. 48-52, 1984.

WINTON, M. D.; CLAYTON, J. S. The impact of invasive submerged weed species on seed banks in lake sediments. Aquatic Bot., v. 53, n. 1, p. 31-45, 1996 